\title{
Quais as principais características organizacionais das empresas dos diferentes segmentos da construção civil?
}

\author{
What are the main organizational characteristics of \\ companies in the different sectors of the civil \\ construction?
}

\section{Alessandra Tourinho Maia Alfredo larozinski Neto}

\section{Resumo \\ $\mathbf{N}$}

este artigo os autores se propõem a identificar os fatores que definem as principais características organizacionais de empresas do subsetor da construção civil, localizadas em Curitiba e região metropolitana, assim como verificar as diferenças existentes entre os cinco segmentos de atividade mais relevantes desse mercado: residencial, industrial e comercial, infraestrutura, serviços especializados e construção industrializada. Para tanto, foi desenvolvida uma pesquisa exploratória e de natureza quantitativa, em nível de mestrado. O método survey foi escolhido como procedimento principal para este estudo, permitindo a obtenção de dados primários por meio da aplicação de um questionário em um grupo de 118 empresas. Esse questionário procurou identificar o perfil da organização e as características organizacionais das empresas avaliadas. Os dados foram analisados com a aplicação de técnicas multivariadas de análise fatorial e análise discriminante. A análise fatorial evidenciou as estratégias de melhoria, o comportamento do indivíduo no trabalho, a estrutura de funcionamento, a dinâmica de crescimento, o estilo de gestão, as relações interpessoais e o posicionamento da empresa perante o mercado como fatores determinantes. A análise discriminante apontou significativa homogeneidade no desenvolvimento organizacional das empresas que representam os diferentes segmentos de atividade.

Palavras-chaves: Empresas de construção civil. Características organizacionais. Análise multivariada.
Alessandra Tourinho Maia Universidade Positivo Curitiba - PR - Brasil

Alfredo larozinski Neto Universidade Tecnológica Federal do Paraná Curitiba - PR - Brasil

Recebido em 08/02/15

Aceito em 01/03/16

\begin{abstract}
The authors' aim was to identify the factors that define the main organizational characteristics among the companies of the civil construction subsector which are located in the city of Curitiba and its metropolitan area, Brazil, as well as to verify the existing differences between the five most relevant activity segments of this market, i.e. residential, industrial and commercial, infrastructure, specialized services, and industrial construction. For this purpose, an applied, exploratory, and quantitative research was developed, at Master's level. The Survey Method was selected as the main procedure for this study, allowing the retrieval of primary data through the application of a questionnaire in a group of 118 companies. The questionnaire aimed at identifying the profile of the organization and the organizational characteristics of the assessed companies. Data were analyzed through inferential statistics by applying multivariate techniques of factor analysis and discriminant analysis. The factor analysis highlighted the improvement strategies, the individual's behavior at work, the organizational structure, the dynamics of growth, management style, interpersonal relationships and the company's orientation towards the market, as key factors. The discriminant analysis showed significant organizational development homogeneity for the companies representing the different sectors of activity.

Keywords: Civil construction companies. Organizational characteristics. Multivariate analysis.
\end{abstract}




\section{Introdução}

A eficácia e a eficiência do funcionamento de uma organização são diretamente influenciadas pela configuração de sua estrutura organizacional. A eficácia está associada à estratégia adotada e a eficiência ao funcionamento da organização. As estratégias organizacionais e a sua relação com as configurações organizacionais têm sido objeto de estudos desenvolvidos com o propósito de ampliar o conhecimento acerca dos elementos determinantes do desempenho organizacional (MINTZBERG, 2003). Uma estrutura organizacional pode ser definida pela delimitação da atividade, pela escolha dos critérios de departamentalização, pela definição do grau de formalização, pela decisão quanto à amplitude de controle e cadeia de comando, pela determinação do nível de descentralização da autoridade, pelo sistema de comunicação, entre outros (VASCONCELLOS; HEMSLEY, 2002; PELLICER et al., 2014). Assim sendo, a presença de deficiências em quaisquer desses aspectos poderá levar a organização a prejuízos estratégicos.

O setor da construção civil é frequentemente criticado por suas deficiências em relação à eficácia de suas estratégias (HÅKANSSON; JAHRE, 2005) e ineficiência da sua gestão (RAZAK BIN IBRAHIM et al., 2010). Entretanto, a influência que o setor exerce sobre a economia nacional e global é clara. Segundo Horta e Camanho (2014), a indústria da construção global representa 9\% do PIB mundial. Esse setor é o maior empregador industrial na maioria dos países, contabilizando $7 \%$ do emprego total em todo o mundo. No Brasil, a construção civil é um dos setores mais relevantes da economia, com mais de 200 mil empresas atuantes no mercado. Fruto do forte desenvolvimento dos últimos dez anos, a maior demanda por atividades do setor tem trazido alguns desafios para o ramo, que tenta se adaptar às exigências do mercado atual, estruturado em ciclos de negócios extensos. Apesar da importância desse setor na economia, sua evolução e modernização não acontecem na mesma intensidade que em outros segmentos industriais (INSTITUTO..., 2014; PRESCOT, 2014).

Tal conjuntura tem levado as empresas brasileiras do setor da construção a buscar maior desempenho em suas estruturas organizacionais, seja por meio de inovações (BEUREN; FLORIANI; HEIN, 2014) ou pela implementação de sistemas integrados de gestão (KRAINER et al.,2013).
Isso posto, este artigo propõe-se a identificar os fatores que definem as principais características organizacionais dos diferentes segmentos da construção civil e as diferenças existentes entre eles.

Para efeito desta pesquisa optou-se por delimitar a investigação das características da estrutura organizacional de empresas de cinco diferentes segmentos de atividade da construção civil, localizadas na região de Curitiba, no Estado do Paraná, a saber: execução de obras residenciais, edificações industriais e comerciais, obras de infraestrutura, serviços especializados para a construção civil, fabricação de estruturas prémoldadas em concreto armado e/ou artefatos de cimento para uso na construção.

\section{Revisão bibliográfica}

Esta seção apresenta o referencial teórico e a revisão da literatura. $\mathrm{O}$ referencial teórico aborda os conceitos e definições encontrados na literatura que são relevantes para este trabalho. A revisão da literatura apresenta um breve levantamento daquilo que já foi publicado em pesquisas relacionadas ao tema deste artigo.

\section{Referencial teórico}

O estudo das estruturas organizacionais constitui um dos pontos centrais da Teoria Geral da Administração e vem sendo tratado de diferentes formas ao longo dos últimos séculos. Os modelos conceituais, desenvolvidos para a sua compreensão, evoluíram muito com o passar do tempo; porém, mesmo assim, os primeiros estudos realizados com foco nessa problemática apresentam muitas ideias que se tornaram a base das teorias mais modernas (VIVANCOS, 2001; OZAKI, 2003).

Segundo Vasconcellos e Hemsley (2002), a estrutura de uma organização pode ser definida como o resultado de um processo por meio do qual a autoridade é distribuída, as atividades são especificadas e um sistema de comunicação é delineado, de modo a permitir que as pessoas realizem as atividades e exerçam a autoridade que lhes compete para atingir os objetivos organizacionais.

Ao longo dos anos, diferentes autores procuraram identificar os fatores componentes e condicionantes das estruturas organizacionais (Quadro 1). 


\section{Quadro 1 - Fatores componentes e condicionantes da estrutura organizacional}

\begin{tabular}{|c|c|}
\hline Autor & Fatores componentes da estrutura organizacional \\
\hline $\begin{array}{l}\text { Burns e } \\
\text { Stalker } \\
(\mathbf{1 9 6 1 )}\end{array}$ & $\begin{array}{l}\text { Representantes da Escola da Contingência, os autores analisam os efeitos do ambiente externo sobre o } \\
\text { padrão de administração e desempenho econômico das empresas. Introduzem a noção de modelo } \\
\text { mecânico, associando a estrutura rígida de uma organização com a de uma máquina em um ambiente } \\
\text { estável; e de modelo orgânico, em que as estruturas são flexíveis e adaptáveis para poder enfrentar o } \\
\text { dinamismo do ambiente. }\end{array}$ \\
\hline $\begin{array}{l}\text { Woodward, } \\
\text { Dawson e } \\
\text { Wedderburn } \\
(1965)\end{array}$ & $\begin{array}{l}\text { Toma como base a investigação de aspectos específicos da organização como: número de níveis de } \\
\text { autoridade, amplitude de controle, forma de definição de deveres, padrão de comunicação e divisão de } \\
\text { funções relacionadas à tecnologia dos sistemas de produção. }\end{array}$ \\
\hline $\begin{array}{l}\text { Vasconcellos } \\
\text { (1972) }\end{array}$ & $\begin{array}{l}\text { Formas de estrutura: tipo de departamentalização. } \\
\text { Divisões de estrutura: níveis hierárquicos que compõem a estrutura. } \\
\text { Sistemas de comunicação. } \\
\text { Amplitude administrativa: número de subordinados que um chefe pode supervisionar. } \\
\text { Responsabilidade e autoridade: identifica quem tem autoridade para executar determinada tarefa e quem } \\
\text { responde pelo seu trabalho (Teoria apresentada por Vasconcellos no ano de 1972, citada por Ozaki } \\
(2003) \text { ). }\end{array}$ \\
\hline $\begin{array}{l}\text { Mintzberg } \\
\text { (1983) }\end{array}$ & $\begin{array}{l}\text { Especialização do trabalho. } \\
\text { Formalização do comportamento. } \\
\text { Treinamento e doutrinação. } \\
\text { Agrupamento e tamanho das unidades. } \\
\text { Sistemas de planejamento e controle. } \\
\text { Dispositivos de ligação. } \\
\text { Descentralização vertical e horizontal. }\end{array}$ \\
\hline $\begin{array}{l}\text { Vasconcellos } \\
\text { e Hemsley } \\
\text { (1989) }\end{array}$ & $\begin{array}{l}\text { A análise de uma estrutura organizacional deve ser realizada com base nos aspectos de definição de } \\
\text { atividade, escolha dos critérios de departamentalização, definição quanto ao nível de centralização, } \\
\text { amplitude de controle e níveis hierárquicos, além do nível de descentralização da autoridade, sistemas } \\
\text { de comunicação e definição quanto ao grau de formalização (citado por Perrotti (2004) e Alves } \\
(2010) \text { ). }\end{array}$ \\
\hline $\begin{array}{l}\text { Dawson } \\
(1992)\end{array}$ & $\begin{array}{l}\text { Indivíduo: atitudes, motivação e performance. } \\
\text { Grupo de interesse: objetivos e estratégia. } \\
\text { Ambiente e mercado. } \\
\text { Tecnologia e organização. } \\
\text { Estrutura: coordenação e controle. }\end{array}$ \\
\hline $\begin{array}{l}\text { Stoner e } \\
\text { Freeman } \\
(1999)\end{array}$ & $\begin{array}{l}\text { Modelo organizacional definido por cinco elementos: a especificação de tarefas, que se refere à divisão } \\
\text { do trabalho e ao nível de departamentalização; a padronização das tarefas; a coordenação das } \\
\text { atividades, composta pelos procedimentos realizados de forma a integrar as funções das subunidades da } \\
\text { organização; a centralização e a descentralização das decisões e o tamanho das unidades de trabalho. }\end{array}$ \\
\hline Pinto (2002) & $\begin{array}{l}\text { O estabelecimento de uma estrutura organizacional pressupõe a definição da divisão do trabalho em um } \\
\text { sistema de responsabilidades, a definição de um sistema de autoridade e de um sistema de } \\
\text { comunicação. }\end{array}$ \\
\hline $\begin{array}{l}\text { Vasconcellos } \\
(\mathbf{2 0 0 3 )}\end{array}$ & $\begin{array}{l}\text { Vasconcellos aprimora o modelo conceitual adotando como componentes principais da estrutura } \\
\text { organizacional o nível de formalização, a departamentalização e as atribuições (citado por Perrotti } \\
(2004)) \text {. }\end{array}$ \\
\hline Hall (2004) & $\begin{array}{l}\text { A estrutura organizacional atende a três funções básicas. Em primeiro lugar, objetiva realizar produtos } \\
\text { organizacionais e atingir metas. Em segundo, destina-se a minimizar ou regulamentar a influência das } \\
\text { variações individuais sobre uma organização. Por fim, as estruturas são os contextos em que o poder é } \\
\text { exercido, as decisões são tomadas e as atividades são executadas. Tais estruturas devem levar em } \\
\text { conta, além do grau de centralização ou descentralização, a formalização e a complexidade do negócio, } \\
\text { ao que se chamam de funções da organização. }\end{array}$ \\
\hline Autor & Fatores condicionantes da estrutura organizacional \\
\hline $\begin{array}{l}\text { Maximiano } \\
(\mathbf{2 0 0 0})\end{array}$ & $\begin{array}{l}\text { Considera como fatores condicionantes o grau de diversificação de produtos e clientes, a ênfase nos } \\
\text { planos e objetivos e a alocação de recursos. }\end{array}$ \\
\hline $\begin{array}{l}\text { Oliveira } \\
(\mathbf{2 0 0 0 )}\end{array}$ & $\begin{array}{l}\text { O fator humano, ambiente externo, sistema de objetivos e estratégias e tecnologia são os fatores que } \\
\text { condicionam o estabelecimento das estruturas organizacionais. }\end{array}$ \\
\hline $\begin{array}{l}\text { Robbins } \\
(2002)\end{array}$ & Adota o tamanho da organização, a estratégia, a tecnologia e o ambiente como fatores condicionantes. \\
\hline $\begin{array}{l}\text { Mintzberg } \\
\quad(2003)\end{array}$ & $\begin{array}{l}\text { As estruturas organizacionais, assim como a divisão do trabalho, as formas de coordenação, } \\
\text { formalização e descentralização, variam de acordo com alguns fatores situacionais como ambiente, } \\
\text { tamanho da organização, tecnologia ou processos produtivos utilizados. }\end{array}$ \\
\hline $\begin{array}{l}\text { Ozaki } \\
(2003)\end{array}$ & $\begin{array}{l}\text { Apresenta um modelo contendo os principais fatores condicionantes da estrutura organizacional: } \\
\text { ambiente externo, fator humano, fator tecnológico e objetivos. }\end{array}$ \\
\hline
\end{tabular}




\section{Revisão da literatura}

Os estudos referentes à organização das empresas da construção civil começaram a ser publicados no final dos anos 1980. Entre eles, o mais relevante é o trabalho de Chang e Choi (1988), que relaciona o impacto da estratégia adotada e os tipos de estruturas organizacionais no desempenho de empresas coreanas do setor da construção.

Durante os anos 1990 e início dos anos 2000 houve um aprofundamento das pesquisas com foco em temas específicos relacionados à Teoria das Organizações. O trabalho de Lansley (1994) é um dos primeiros a se destacar na aplicação dos conceitos da Teoria das Organizações, no entendimento e na análise do funcionamento de empresas da construção civil. $\mathrm{O}$ autor aborda o impacto dos estilos de liderança e da estrutura organizacional no desempenho global da empresa.

Shirazi, Langford e Rowlinson (1996) sugerem uma maior descentralização da estrutura de gestão em função da complexidade das atividades da construção civil. No mesmo sentido Kim (1997) apresenta um estudo que mostra a necessidade de descentralização e flexibilização das estruturas organizacionais das empresas de construção em face da complexidade dos projetos e das exigências do ambiente concorrencial.

Cabe destacar, também, o trabalho de Handa e Adas (1996), um dos pioneiros nas pesquisas que relacionam as características organizacionais e a eficácia organizacional. Esse estudo utiliza um modelo de 14 variáveis com o objetivo de predizer o nível de eficácia organizacional nas empresas de construção.

Vivancos (2001) avalia as características das estruturas organizacionais de pequenas e médias empresas construtoras de edifícios, localizadas no estado de São Paulo, através de quatro estudos de caso. O autor conclui que se trata de estruturas centralizadas nas quais predomina a comunicação formal no sentido vertical descendente.

Outro estudo de destaque no tema é o apresentado por Dikmen, Birgonul e Kiziltas (2005). Essa pesquisa, fundamentada em dados coletados em 116 empresas de construção localizadas na Turquia, com base em uma pesquisa survey, procura identificar os principais parâmetros relacionados à eficácia organizacional.

Benson (2010) investiga a gestão da flexibilidade organizacional de empresas de construção em Cingapura. Segundo o autor, a flexibilidade pode ser influenciada, em diferentes graus, pelos seguintes fatores: cultura de aprendizagem organizacional, estrutura organizacional, aptidões e comportamento dos trabalhadores, capacidades da cadeia de suprimentos e estratégias de negócios. Outras pesquisas procuram relacionar as características organizacionais e as características do mercado (KIM; REINSCHMIDT, 2011), com a cultura da organização (CHEUNG; WONG; LAM, 2012) e as decisões estratégias adotadas (ISIK; ARDITI; BIRGONUL, 2010) com o desempenho das empresas.

As pesquisas mais recentes se caracterizam por apresentar temas que relacionam as características organizacionais das empresas da construção a aspectos específicos. Os aspectos de maior destaque são: a segurança (LINGARD; COOKE; GHARAIE, 2013; CAMERON; HARE; DUFF, 2013; KOH; ROWLINSON, 2012; SHEN et al., 2015), a cadeia de suprimentos (SEGERSTEDT; OLOFSSON, 2010), a internacionalização de mercados (YANG; LU, 2013), a gestão do conhecimento (BAKAR; VIRGIYANTI; TUFAIL, 2012; MOHAMMED ALASHWAL; ABDULRAHMAN, 2014), as práticas de motivação e formação dos recursos humanos (TABASSI; RAMLI; BAKAR, 2012; ZHAI; LIU; FELLOWS, 2013), a gestão de riscos (CHILESHE; JOHN KIKWASI, 2014; ROSTAMI et al., 2015) e a logística (BELLAH; ZELBST; GREEN JUNIOR, 2013; ABARESHI; MOLLA, 2013).

A diversificação dos temas de pesquisa mostra uma tendência para se buscar um entendimento mais detalhado acerca das relações entre o desempenho de determinados aspectos e as configurações organizacionais das empresas de construção civil.

\section{Estratégia metodológica}

Para a concretização do objetivo deste estudo foi realizada uma pesquisa de natureza aplicada, objetivo exploratório e abordagem quantitativa. O método survey foi escolhido como procedimento principal, o que permite a obtenção de dados primários de forma sistematizada através do emprego de um questionário. A Figura 1 ilustra a estratégia metodológica da pesquisa. A descrição do problema e a revisão bibliográfica estão apresentadas em seções anteriores. O desenvolvimento do método survey e os procedimentos de análise dos dados são descritos a seguir.

\section{Procedimento baseado no método survey}

O método survey foi escolhido em função da necessidade de se descrever a situação atual das empresas de construção civil em relação à sua estrutura organizacional. Segundo Babbie (1999), 
o survey funciona como um mecanismo exploratório, aplicado em uma situação de investigação inicial de algum tema, que busca não permitir que elementos críticos deixem de ser identificados e apresenta novas possibilidades que podem posteriormente ser trabalhadas em um survey mais controlado.

As surveys podem ser empregadas quando o estudo envolve a coleta de informações de uma grande amostra de indivíduos (FREITAS et al., 2000; HAIR JUNIOR et al., 2005). Nesta pesquisa, a coleta de dados foi efetuada em corte transversal. De acordo com Hair Jr. et al. (2005) esse procedimento visa descrever e analisar o estado das variáveis, que posteriormente serão tratadas estatisticamente, em determinado momento.

\section{Planejamento do survey}

O planejamento do survey pode ser dividido em quatro etapas: a identificação da necessidade de informações, a escolha das variáveis, a delimitação da população-alvo e amostra e, por fim, a definição e o desenvolvimento do instrumento de coleta e mensuração de dados (HAIR JUNIOR et al., 2005).

Para que se inicie o planejamento do survey é necessário definir os dados que serão levantados de modo a gerar informações acerca do tema pesquisado (HAIR JUNIOR et al., 2005). Nesta pesquisa não houve a preocupação em se levantar os dados associados a um modelo ou teoria organizacional específica, uma vez que a escolha das variáveis com base em uma única teoria poderia limitar o espectro da análise. Além disso, por se tratar de uma pesquisa exploratória, em um primeiro momento, optou-se pela adoção de uma ampla gama de variáveis que pudessem descrever as características organizacionais das empresas dos diferentes setores da construção civil, para que, em um segundo momento, fosse possível identificar variáveis mais específicas, associadas às teorias e aos modelos organizacionais. Assim sendo, a partir da pesquisa empírica é que determinadas teorias e modelos organizacionais se mostraram mais ou menos adequados ao estudo das particularidades do setor da construção civil.

Figura 1 - Estratégia metodológica

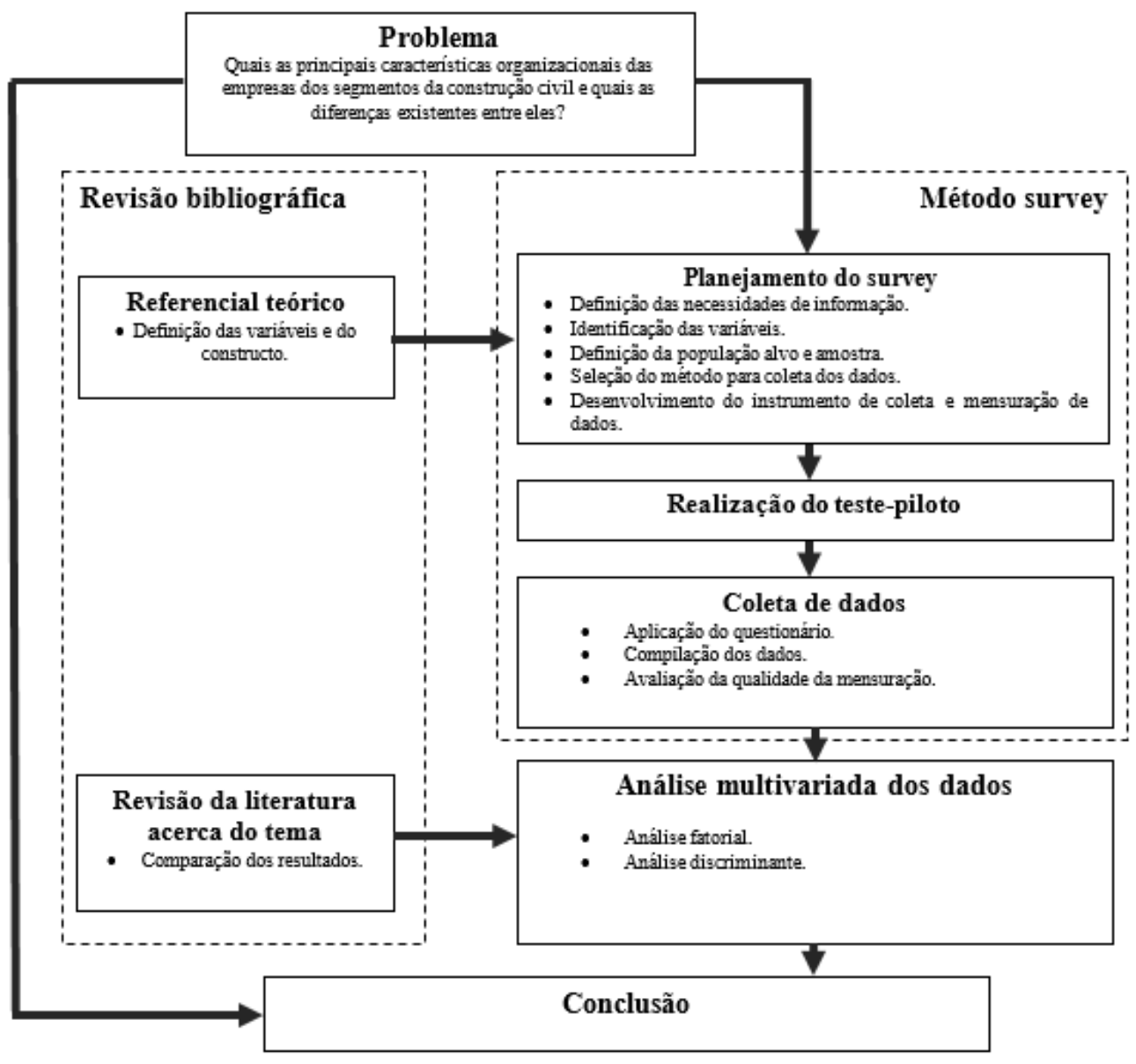


Portanto, os dados utilizados como base para a elaboração do instrumento de coleta de dados estão relacionados ao estilo de gestão, ao nível de formalização, ao grau de integração entre funcionários, ao investimento em qualificação dos funcionários, ao nível de integração, desenvolvimento e controle de processos, ao grau de investimentos, e a outras características organizacionais destacadas por autores como Woodward, Dawson e Wedderburn (1965), Mintzberg (1983), Vivancos (2001), Vasconcelos e Hemsley (2002), Ozaki (2003) e Hall (2004).

Em regra, esses dados podem ser associados a um conjunto de variáveis sistematizadas no formato de um questionário, que podem ser mensuradas pelo uso de escalas nominais e ordinais. Esse procedimento permite que os dados sejam tratados com o emprego de ferramentas estatísticas visando à obtenção de informações acerca da amostra. A definição das variáveis desta pesquisa foi orientada de modo a se obter o maior número possível de variáveis que poderiam ser avaliadas e mensuradas, e que refletissem, no seu conjunto, as principais características organizacionais das empresas pesquisadas, de forma que cada variável fosse relativamente homogênea e independente das demais. O Quadro 2 sumariza o conjunto das variáveis empregadas nesta pesquisa.

A população-alvo desta pesquisa é constituída por empresas de construção civil, localizadas na região de Curitiba, Estado do Paraná, que têm como atividade principal um dos seguintes segmentos: execução de obras residenciais, edificações industriais e comerciais, obras de infraestrutura, serviços especializados para a construção civil, fabricação de estruturas pré-moldadas em concreto armado e/ou artefatos de cimento para uso na construção. Esses cinco segmentos, respectivamente denominados de residencial, industrial e comercial, infraestrutura, serviços especializados e construção industrializada, foram estabelecidos de acordo com a Classificação Nacional de Atividades Econômicas (CNAE), versão 2.0 (2007), proposta pelo Instituto Brasileiro de Geografia e Estatística (IBGE, 2013).

Quadro 2 - Variáveis associadas às características organizacionais

\begin{tabular}{|c|c|}
\hline $\begin{array}{l}\text { Notação da } \\
\text { variável }\end{array}$ & Descrição da variável \\
\hline $\mathrm{X} 29$ & Nível de centralização da estrutura organizacional. \\
\hline $\mathrm{X} 30$ & Nível de formalização dos cargos e funções. \\
\hline $\mathrm{X} 31$ & Estilo de gestão da empresa. \\
\hline $\mathrm{X} 32$ & Média de horas de treinamento/ano. \\
\hline X33 & Nível de formalização das atividades e processos. \\
\hline X34 & Grau de autonomia dos funcionários. \\
\hline X35 & Grau de especialização dos funcionários. \\
\hline X36 & Nível de departamentalização. \\
\hline X37 & Nível de integração entre os processos. \\
\hline $\mathrm{X} 38$ & Taxa de crescimento da empresa nos últimos três anos. \\
\hline X39 & Nível de formação dos funcionários. \\
\hline $\mathrm{X} 40$ & Nível de cooperação entre os funcionários. \\
\hline $\mathrm{X} 41$ & Nível de interação entre os funcionários. \\
\hline $\mathrm{X} 42$ & Nível de controle exercido sobre as atividades e/ou funcionários. \\
\hline $\mathrm{X} 43$ & Nível de investimento em tecnologias e equipamentos, realizado nos últimos três anos. \\
\hline $\mathrm{X} 44$ & Posição da empresa em relação aos seus concorrentes. \\
\hline $\mathrm{X} 45$ & Tempo de resposta da empresa às demandas do mercado \\
\hline $\mathrm{X} 46$ & Capacidade da empresa em se adaptar às mudanças do seu mercado/ambiente. \\
\hline $\mathrm{X} 47$ & Características de dinamismo do mercado em que a empresa atua. \\
\hline $\mathrm{X} 48$ & Comportamento da empresa em relação às tendências do mercado. \\
\hline $\mathrm{X} 49$ & Nível de formalização nas relações entre os funcionários. \\
\hline $\mathrm{X} 50$ & Nível de conhecimento dos funcionários em relação às estratégias de gestão. \\
\hline X51 & Posição da empresa em relação à redução de custos em suas atividades ou processos. \\
\hline X52 & Nível de preocupação da empresa em relação à adoção de melhorias nos processos. \\
\hline X53 & Nível de preocupação da empresa em relação à prevenção de problemas. \\
\hline X54 & Avaliação das habilidades necessárias aos funcionários para a execução de suas atividades. \\
\hline X55 & $\begin{array}{l}\text { Nível de alinhamento das características dos empreendimentos, produtos ou serviços com a } \\
\text { estratégia adotada pela empresa. }\end{array}$ \\
\hline X56 & $\begin{array}{l}\text { Nível de preocupação com a diferenciação de seus empreendimentos, produtos ou serviços em } \\
\text { relação aos seus concorrentes. }\end{array}$ \\
\hline X57 & Evolução do quadro de funcionários nos últimos três anos. \\
\hline
\end{tabular}

202 Maia, A. T.; larozinski Neto, A. 
Em função do grande número de empresas de construção civil com sede na região delimitada para essa amostra e da dificuldade de adesão da totalidade dessas empresas à pesquisa, optou-se pelo método de amostragem não probabilística por conveniência. Esse tipo de amostra envolve a seleção de elementos de amostra que estejam mais disponíveis para tomar parte no estudo e que podem oferecer as informações necessárias (HAIR JUNIOR et al., 2005). Dessa forma, a amostra de empresas selecionadas na presente pesquisa não pode ser considerada como representativa da população-alvo, não sendo possível efetuar extrapolações e generalizações acerca dos resultados com grau mensurado de segurança.

$\mathrm{O}$ instrumento de coleta de dados adotado nesta pesquisa é um questionário desenvolvido com base nos instrumentos de pesquisa testados $\mathrm{e}$ empregados recentemente nas pesquisas de Yuki (2011), Mainardes (2012) e Krainer et al. (2013), relacionadas às características organizacionais das empresas de construção civil. Este questionário está dividido em duas partes: perfil da organização e do entrevistado e características da organização.

O perfil da organização (composto por 11 questões abertas e 8 questões fechadas de múltipla escolha) compreende a identificação do perfil da organização e do entrevistado, com destaque para o setor de atividade principal, o ano de fundação da empresa, o número de funcionários, a forma de constituição e de administração, o número de certificações, a produção anual, assim como a área de formação do respondente e o seu tempo de atuação profissional na empresa avaliada.

A segunda parte do questionário, relativa às características organizacionais, é composta por 29 questões fechadas relacionadas às variáveis apresentadas no Quadro 3, que procuraram refletir o nível de centralização e formalização, o estilo de liderança, o grau de autonomia, os critérios de departamentalização, o investimento em treinamento, entre outras características de interesse.

A mensuração quantitativa dessas características se deu por meio da adoção de uma escala de diferencial semântico e intensidade crescente. De acordo com Aguiar, Correia e Campos (2011), escalas de diferencial semântico são aquelas em que cada item avaliado é polarizado em dois adjetivos (ou frases descritivas) opostos e contrários. A escala adotada nesta pesquisa, exemplificada no Quadro 3, é composta por sete graus, postos entre dois adjetivos ou frases descritivas antônimas em que o respondente deve escolher o grau que melhor representa sua opinião.
É relevante considerar que, em função de erros de mensuração, como, por exemplo, o viés de concordância em que os respondentes tendem a avaliar favoravelmente todos os atributos, o emprego de escalas acrescenta um caráter subjetivo às análises (SAMARTINI, 2006). Portanto, os resultados finais obtidos devem ser analisados como tendências e não como valores absolutos.

\section{Teste-piloto do questionário}

Inicialmente, realizou-se um teste-piloto do questionário em uma amostra de dez empresas da população-alvo. Nesse momento, o questionário foi administrado pessoalmente pelos pesquisadores, o que permitiu a análise da provável exatidão e da coerência das respostas. Nessa etapa foi possível esclarecer algumas dúvidas e definir conceitos eventualmente não compreendidos, minimizando-se, por consequência, possíveis erros. Após o pré-teste, alguns ajustes foram efetuados para que se iniciasse a aplicação do questionário.

\section{Coleta de dados}

Cerca de 450 empresas foram previamente contatadas e convidadas a participar desta pesquisa, cuja meta mínima de amostragem prevista era de 100 empresas. A amostra final, no entanto, é constituída por 118 empresas. A coleta de dados perdurou por oito meses, no período compreendido entre novembro de 2013 e julho de 2014.

Aproximadamente $15 \%$ da amostra foi obtida através do envio eletrônico de questionários autoadministrados, gerenciados por intermédio da ferramenta Formulários Google, às empresas de construção civil, localizadas na região de Curitiba, integrantes da base de dados da regional sul da Associação Brasileira de Cimento Portland (ABCP). Com a finalidade de garantir a confiabilidade dos dados coletados, preliminarmente contatou-se a alta direção dessas empresas. A partir da sua anuência e da indicação de possíveis respondentes, o questionário era apresentado e o link para a resposta disponibilizado.

Os demais questionários foram obtidos durante as aulas dos cursos de pós-graduação da Universidade Tecnológica Federal do Paraná (UTFPR) e do Serviço Nacional de Aprendizagem Industrial (SENAI-PR), cujos alunos integravam o quadro funcional de empresas que se adequavam na descrição da população-alvo. Nessa etapa, os objetivos da pesquisa e o questionário foram apresentados pessoalmente pelos pesquisadores, 
que permaneceram disponíveis para elucidar quaisquer dúvidas que pudessem surgir durante o preenchimento.

Contudo, é importante destacar que a pesquisa foi respondida por profissionais de diferentes níveis hierárquicos das empresas, imprimindo caráter subjetivo aos dados. De todo modo, ressalta-se que o tempo médio de atuação desses respondentes nas respectivas empresas é de três anos, o que confere maior autenticidade às informações. Segundo
Perdigão, Herlinger e White (2012), o caráter subjetivo das pesquisas tem sido apontado como uma de suas principais limitações pelo fato de os resultados não poderem ser generalizados nem projetáveis para a população; entretanto, ao mesmo tempo, os autores consideram que a subjetividade é o que garante a riqueza e a profundidade dos resultados.

O Quadro 4 apresenta um resumo dos principais elementos que caracterizam essa amostra.

Quadro 3 - Modelo de escala de diferencial semântico

\begin{tabular}{|l|l|l|l|l|l|l|l|l|}
\hline Centralizada & 1 & 2 & 3 & 4 & 5 & 6 & 7 & Descentralizada \\
\hline Sem formalização & 1 & 2 & 3 & 4 & 5 & 6 & 7 & Totalmente formalizada \\
\hline Autocrática & 1 & 2 & 3 & 4 & 5 & 6 & 7 & Democrática \\
\hline
\end{tabular}

\section{Quadro 4 - Perfil da amostra}

\begin{tabular}{|c|c|}
\hline \multirow{2}{*}{ Parâmetro } & Referência \\
\hline & PERFIL DA ORGANIZAÇÃO \\
\hline Segmento de atuação & $\begin{array}{l}43 \% \text { da amostra - Construtoras que atuam no segmento residencial. } \\
14 \% \text { - Construtoras que atuam no ramo de infraestrutura. } \\
12 \% \text { - Empresas que atuam no ramo de execução de edificações industriais, } \\
\text { comerciais e outras edificações não residenciais. } \\
18 \% \text { - Empresas que atuam no ramo de serviços especializados. } \\
12 \% \text { - Empresas classificadas como construção industrializada. }\end{array}$ \\
\hline Ano de fundação & $\begin{array}{l}25 \% \text { da amostra - Empresas fundadas até } 1980 \text {. } \\
46 \% \text { - Empresas fundadas no período compreendido entre os anos de } 1980 \text { e } \\
2000 \text {. } \\
29 \% \text { - Empresas fundadas a partir de } 2001 \text {. }\end{array}$ \\
\hline Tipo de administração & $\begin{array}{l}\text { 41\% - Empresas familiares. } \\
50 \% \text { - Administração profissional. } \\
9 \% \text { - Administração mista. }\end{array}$ \\
\hline Constituição & $\begin{array}{l}78 \% \text { - Empresas tipo limitadas. } \\
10 \% \text { - S.A. de capital fechado. } \\
5 \% \text { - S.A. de capital aberto. } \\
1 \% \text { - S.A. de capital misto. } \\
7 \% \text { restantes - Classificadas como outros. }\end{array}$ \\
\hline Número de funcionários & $\begin{array}{l}\text { 37\% - Microempresas (até } 19 \text { funcionários). } \\
25 \% \text { - Pequenas empresas (de } 20 \text { a } 99 \text { funcionários). } \\
18 \% \text { - Empresas de médio porte (de } 100 \text { a } 499 \text { funcionários). } \\
20 \% \text { - Grandes empresas (acima de } 499 \text { funcionários). }\end{array}$ \\
\hline $\begin{array}{l}\text { Área de atuação do } \\
\text { entrevistado }\end{array}$ & $\begin{array}{l}65 \% \text { - Engenharia e desenvolvimento. } \\
17 \% \text { - Administrativa. } \\
6 \% \text { - Produção. }\end{array}$ \\
\hline $\begin{array}{l}\text { Cargo ocupado pelo } \\
\text { entrevistado }\end{array}$ & $\begin{array}{l}38 \% \text { - Engenheiros e arquitetos. } \\
33 \% \text { - Diretores e gerentes. } \\
13 \% \text { - Coordenadores, assessores e analistas. } \\
8 \% \text { - Técnicos, operadores, auxiliares. } \\
8 \% \text { - Trainees e estagiários. }\end{array}$ \\
\hline $\begin{array}{l}\text { Tempo de atuação do } \\
\text { entrevistado na empresa }\end{array}$ & $\begin{array}{l}79 \% \text { - Tempo médio de } 3 \text { anos. } \\
8 \% \text { - Entre } 7 \text { e } 10 \text { anos. } \\
3 \% \text { - Entre } 11 \text { e } 15 \text { anos. } \\
6 \% \text { - Entre } 16 \text { e } 20 \text { anos. } \\
4 \% \text { - Acima de } 20 \text { anos. }\end{array}$ \\
\hline
\end{tabular}

204 Maia, A. T.; larozinski Neto, A. 


\section{Procedimento de análise dos dados}

Os dados coletados foram analisados por intermédio da estatística inferencial, com a aplicação das técnicas multivariadas de análise fatorial e análise discriminante. $\mathrm{O}$ objetivo da análise, em um primeiro momento, foi identificar os fatores que mais se destacam em relação às características organizacionais das empresas do setor da construção civil. Em seguida buscou-se identificar, entre esses fatores, os que mais contribuem para as diferenças entre os cinco segmentos de atividade e analisar a existência de diferenças estatisticamente significantes entre eles. Para cumprir esses objetivos foi necessário empregar as etapas metodológicas apresentadas na Figura 2. A ferramenta adotada para o desenvolvimento da análise multivariada foi o Statistical Package for the Social Sciences (SPSS).

\section{Análise fatorial}

A análise fatorial é uma técnica estatística que tem como objetivo reduzir o número de variáveis iniciais com a menor perda possível de informação. O resultado é obtido analisando-se os inter-relacionamentos entre as variáveis, de tal modo que elas possam ser descritas convenientemente por um grupo de categorias básicas, em menor número que as variáveis originais, denominadas de fatores ou variáveis latentes (VICINI; MENDONÇA, 2005). Os fatores identificados pela análise fatorial são uma descoberta feita pelo pesquisador.

$\mathrm{Na}$ análise desses fatores comuns as variáveis são agrupadas em função de suas correlações. Isso significa que as variáveis que compõem um determinado fator devem ser altamente correlacionadas entre si e fracamente correlacionadas com aquelas que compõem o outro fator. $\mathrm{O}$ modelo de análise fatorial estima os fatores e as variâncias, de modo que as covariâncias ou correlações previstas estejam o mais próximo possível dos valores observados (RODRIGUES, 2002; BISQUERRA; SARRIERA; MARTINEZ, 2007).

Figura 2 - Etapas da análise

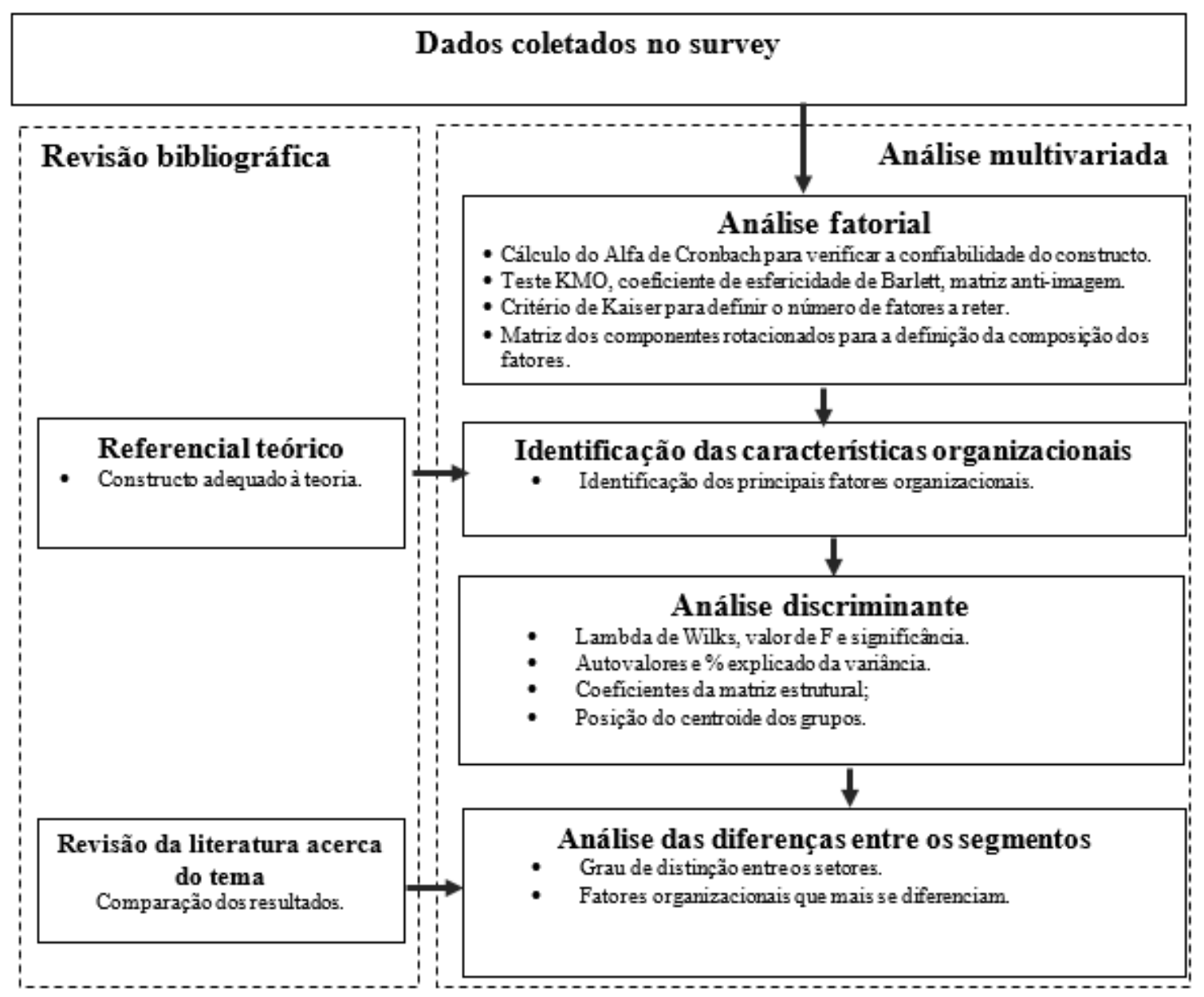


Para efeito deste trabalho adotou-se um dos métodos mais utilizados para a extração dos fatores: a análise de componentes principais. Segundo Vicini e Mendonça (2005), essa análise baseia-se no pressuposto que se pode definir " $X$ " vetores estatisticamente não correlacionados a partir de combinações lineares dos $\rho$ indicadores iniciais e permite transformar um conjunto de variáveis iniciais, correlacionadas entre si, em outro conjunto de variáveis não correlacionadas (ortogonais) que resultam das combinações lineares do conjunto inicial.

Contudo, de acordo com Bakke, Moura Leite e Leite (2008), um fator crucial que deve anteceder a aplicação da análise fatorial é a análise de confiabilidade interna do constructo utilizado na obtenção dos dados. Maroco e Garcia-Marques (2006) citam que dentre os diferentes métodos que fornecem estimativas do grau de consistência de um instrumento destaca-se o índice alfa de Cronbach, modelo sugerido como conservador especialmente nos casos em que os itens da escala são heterogêneos, dicotômicos ou definem estruturas multifatoriais.

Para efeito desta pesquisa, a avaliação da adequação amostral e o desenvolvimento da análise fatorial se deram através dos seguintes passos: análise da matriz de correlações, teste $\mathrm{KMO}$, teste de esfericidade de Bartlett, matriz antiimagem e comunalidades. Em seguida foram analisados o número de fatores retidos, através do critério de Kaiser, e a matriz de componentes rotacionados, após a rotação varimax, e então foram obtidos os escores fatoriais utilizados na análise discriminante.

\section{Análise discriminante}

O método de análise discriminante tem por objetivo determinar as variáveis que diferenciam ou discriminam grupos, permitindo assim a identificação de grupos similares e a classificação de novos casos, em que a inserção desses elementos ocorre no grupo a que o elemento tem a maior probabilidade de pertencer (SOUZA, 2006).

Em virtude de o número inicial de variáveis empregadas nesta pesquisa ser relativamente elevado (29 variáveis), poderia não ocorrer uma adequada proporção entre o tamanho da amostra (total e por grupos) e o número de variáveis, provocando possíveis distorções no resultado da análise discriminante. Desse modo, utilizou-se como base da análise discriminante (variáveis independentes) os fatores resultantes da análise fatorial. Isso possibilita adotar um número relativamente menor de variáveis alternativas, não correlacionadas, e que, de algum modo, sumarizem as informações principais das variáveis iniciais, sem perda significativa da informação contida nos dados originais e sem os problemas que a existência da multicolinearidade pode provocar no resultado da análise (MAROCO, 2003; BAKKE; MOURA LEITE; SILVA, 2008).

O primeiro passo para a realização de uma análise discriminante envolve o teste das suposições relativas à análise multivariada, a saber: a normalidade multivariada das variáveis independentes, a homogeneidade das matrizes de variância e covariância, e a ausência de multicolinearidade e linearidade das variáveis.

Depois de verificados todos esses pressupostos, o passo seguinte consiste em efetuar a análise preliminar das variáveis independentes, com o objetivo de verificar a existência de diferenças entre as médias e testar a significância das funções discriminantes, através do teste de igualdade entre as médias e do lambda de Wilks.

Os coeficientes estruturais de Pearson, agrupados de acordo com a correlação dentro dos grupos, entre as variáveis explicativas e as funções discriminantes canônicas padronizadas, estão representados na matriz estrutural. Essa matriz auxilia na interpretação da contribuição que cada variável forneceu para cada função discriminante.

Uma maneira de interpretar os resultados da análise discriminante é descrever cada grupo em termos de seu perfil, utilizando o valor médio do escore discriminante para uma determinada categoria de variável. Esses coeficientes, denominados centroides, são representados graficamente em um mapa territorial (MAROCO, 2003).

A análise das matrizes de classificação representa outra maneira de se avaliar a validade da análise discriminante. Uma vez obtida a função discriminante, calculam-se os escores discriminantes para cada observação, e, através da comparação com os valores dos centroides, reclassificam-se os elementos a partir das variáveis dependentes. A etapa seguinte consiste em comparar a variável reclassificada com seu valor original, obtendo-se um percentual de casos "corretamente classificados" (ANDREASSI; SBRAGIA, 2001).

\section{Análise dos resultados}

Nesta seção é apresentada a análise dos resultados obtidos a partir da estratégia metodológica adotada. A primeira subseção resume os resultados da análise fatorial, apontando os fatores organizacionais de destaque nas empresas de construção civil. A subseção seguinte destaca, por 
meio de análise discriminante, as características organizacionais que mais diferenciam os cinco segmentos de atividade.

\section{Análise fatorial}

Analisando-se o conjunto das 29 variáveis utilizadas, através do modelo de alfa de Cronbach, percebe-se que o constructo e a escala adotados nesta pesquisa apresentam boa confiabilidade interna, uma vez que o valor obtido foi de 0,886 , muito superior ao mínimo ideal sugerido de 0,600 , e conclui-se que os dados são adequados ao propósito para o qual foram designados.

Verificando-se os pressupostos para o desenvolvimento da análise fatorial, o resultado do teste KMO sugere que há boa adequação da amostra quanto ao grau de correlação parcial entre as variáveis, uma vez que ofereceu o valor de 0,824. Esse resultado é ratificado pelo teste de esfericidade de Bartlett, que tem associado um nível de significância de 0,000 , valor inferior a 0,050, o que leva a rejeitar a hipótese de a matriz das correlações entre as variáveis ser a matriz identidade, mostrando, portanto, que existe correlação entre as variáveis.

A matriz anti-imagem mede a adequação amostral de cada variável. A matriz obtida nessa análise valida a permanência das 29 variáveis na análise fatorial. $\mathrm{O}$ resultado das comunalidades, extraídas através do método da análise de componentes principais, avalia a contribuição da variável ao modelo construído pela análise fatorial. Como todas as variáveis extraídas apresentaram valor superior a 0,500 , foram mantidas na análise.

O critério de Kaiser determina o número de fatores a reter em função do número de valores próprios maiores que 1,000. Nesta pesquisa, sete fatores, que explicam $63,2 \%$ da associação total entre as variáveis, foram escolhidos como relevantes.

A matriz de componentes dos fatores rotacionados pelo método varimax está apresentada no Anexo. Para se chegar à escolha do método varimax, inicialmente optou-se por uma projeção ortogonal de modo que os fatores resultantes fossem os mais independentes possíveis. Nesse caso, a tendência é obter fatores mais homogêneos e mais representativos (COMREY; LEE, 2013). As rotações oblíquas são difíceis de interpretar e se prestam a estudos bem específicos em que se pretende detalhar a ação conjunta das variáveis estudadas (CURETON; D’AGOSTINHO, 2013).
Para a rotação do tipo ortogonal há três métodos possíveis: o varimax, o quartimax e o equimax. $\mathrm{O}$ método varimax busca minimizar o número de variáveis que cada agrupamento terá, resultando em um menor número de fatores que serão identificados. O método quartimax, ao contrário, tenta minimizar o número de fatores necessários para explicar uma variável, ou seja, ter-se-á um maior número de variáveis por fator. Finalmente, o método equimax é um compromisso entre os métodos anteriores, ou seja, pretende reduzir o número de fatores e, ao mesmo tempo, o número de variáveis por fator (COSTELLO, 2009). Como o objetivo final deste trabalho é identificar os principais fatores associados às características organizacionais das empresas dos diversos segmentos da construção civil e usá-los para identificar as diferenças existentes entre eles, entende-se que o método varimax é o que mais contribui para esse objeto, uma vez que tende a gerar um maior número de fatores (COMREY; LEE, 2013; COSTELLO, 2009).

A maior quantidade de fatores e sua independência contribuem para melhor entendimento da distinção entre os segmentos. Os fatores são a agregação das variáveis iniciais da pesquisa. Se o número de fatores é pequeno (e por consequência a agregação das variáveis iniciais é grande), a distinção entre os segmentos torna-se mais difícil de ser caracterizada. Ao contrário, se o número de fatores identificados é maior, a distinção se torna mais “detalhada" e mais fácil de ser caracterizada. Além disso, a redução de fatores proporcionada pelos outros métodos ocasionaria uma perda significativa de informação contida nos dados (HAIR JUNIOR et al., 2005). A escolha das variáveis que compõem cada um dos sete fatores se deu por meio da observação das cargas fatoriais de cada variável.

Os fatores determinados pela análise fatorial indicam a existência de um conjunto de características que mais se destacam dentro do grupo de variáveis avaliadas. Tais fatores foram renomeados de acordo com as características comuns daquelas variáveis que os representam (Quadro 5). De certa forma, esses fatores representam os constructos derivados das diversas abordagens da Teoria Organizacional, dos tipos e modelos de estruturas e dos fatores componentes e condicionantes da estrutura organizacional apresentados na revisão da literatura. 
Quadro 5 - Composição dos fatores

\begin{tabular}{|c|c|c|l|}
\hline Fator & Variáveis representativas & $\begin{array}{c}\text { Variância } \\
\text { explicada (\%) }\end{array}$ & \multicolumn{1}{|c|}{ Nome do fator } \\
\hline 1 & $\mathrm{X} 42, \mathrm{X} 46, \mathrm{X} 52, \mathrm{X} 53, \mathrm{X} 54, \mathrm{X} 55, \mathrm{X} 56$ & $15,195 \%$ & "Estratégias de melhoria" \\
\hline 2 & $\mathrm{X} 40, \mathrm{X} 41, \mathrm{X} 50$ & $10,650 \%$ & "Comportamento do indivíduo no trabalho" \\
\hline 3 & $\mathrm{X} 30, \mathrm{X} 32, \mathrm{X} 33, \mathrm{X} 36$ & $10,650 \%$ & "Estrutura de funcionamento" \\
\hline 4 & $\mathrm{X} 38, \mathrm{X} 44, \mathrm{X} 57$ & $8,453 \%$ & "Dinâmica de crescimento" \\
\hline 5 & $\mathrm{X} 29, \mathrm{X} 31, \mathrm{X} 34$ & $6,745 \%$ & "Estilo de gestão" \\
\hline 6 & $\mathrm{X} 39, \mathrm{X} 49, \mathrm{X} 51$ & $6,684 \%$ & "Relações interpessoais" \\
\hline 7 & $\mathrm{X} 47$ & $4,833 \%$ & "Posicionamento perante o mercado" \\
\hline
\end{tabular}

Observa-se que na composição do fator 1 , "estratégias de melhorias", as variáveis que representam o nível de preocupação das empresas em relação à adoção de melhorias nos processos e à prevenção de problemas, bem como as habilidades dos funcionários para a execução de suas atividades e o nível de alinhamento das características dos produtos com a estratégia adotada pelas empresas, estão positivamente relacionadas e são as que mais se destacam, demonstrando que a necessidade de melhoria é um componente de destaque nas características das organizações de construção civil.

O segundo fator, "comportamento do indivíduo no trabalho", ressalta o nível de cooperação e interação entre os funcionários. Esse fato possivelmente deriva das necessidades impostas pelo contexto e peculiaridades em que ocorrem as atividades da construção.

O terceiro fator, "estrutura de funcionamento", por sua vez, representa alguns dos principais fatores condicionantes da estrutura organizacional através dos níveis de formalização de cargos e funções, atividades e processos e dos critérios de departamentalização das empresas, caracterizando a estrutura de funcionamento das organizações.

O quarto fator destaca a "dinâmica de crescimento" das empresas através da correlação positiva entre a taxa de crescimento da empresa e a evolução do quadro de funcionários nos últimos três anos, bem como a atuação das empresas diante de seus concorrentes.

O quinto fator indica o "estilo de gestão" das empresas, através da composição de outros três importantes fatores condicionantes da estrutura organizacional: as características de centralização, o estilo de gestão e o grau de autonomia dos funcionários.

O sexto fator, "relações interpessoais", é composto por três variáveis, duas das quais se relacionam negativamente com o fator, demonstrando que quanto maior o nível de formação dos funcionários, menor o nível de formalização entre suas relações interpessoais.
Por fim, o sétimo fator, composto apenas por uma variável, indica as características de dinamismo do mercado em que as empresas estão inseridas.

Os resultados obtidos pela análise fatorial demonstram que os fatores organizacionais identificados nesta pesquisa não diferem muito daqueles identificados em estudos realizados no Brasil e em outros países. As estratégias de melhoria aparecem com destaque nos trabalhos que estudam a eficiência organizacional (HANDA; ADAS, 1996; DIKMEN; BIRGOUNUL; KIZILTAS, 2005; ZAYED; ELWAKIL; AMMAR, 2012). O comportamento do indivíduo no trabalho e a estrutura de funcionamento são uma constante em praticamente todas as pesquisas realizadas acerca do tema. $\mathrm{O}$ estilo de gestão também é frequentemente analisado, merecendo destaque em alguns estudos específicos (SHIRAZI; LANGFORD; ROWLINSON, 1996; KIM, 1997). A dinâmica do crescimento do setor e o posicionamento das empresas perante o mercado se destacam em estudos mais recentes que correlacionam as características organizacionais, o desempenho e o mercado (KIM; REINSCHMIDT, 2011; ISIK; ARDITI; BIRGONUL, 2010).

\section{Análise discriminante}

Inicialmente foram verificados os pressupostos da análise discriminante, apresentados na metodologia desta pesquisa. O resultado do teste de Kolmogorov-Smirnov para os sete fatores apresentou $p$-value (sig.) $>0,050$, não rejeitando a hipótese nula $\left(\mathrm{H}_{0}\right)$, subentendendo-se, portanto, que a distribuição normal é uma distribuição possível para o conjunto de dados em questão.

A existência de homogeneidade das matrizes de variância e covariância entre os grupos é verificada através do teste $\mathrm{M}$ de Box. Os resultados indicam que a hipótese de igualdade das matrizes de variância e covariância encontra sustentação, uma vez que o p-value encontrado é 0,282 , maior que o nível de significância $(\alpha)$ adotado. Pela análise das correlações entre as variáveis conclui-se que não há problemas de multicolinearidade entre as 
variáveis independentes, o que ratifica a permanência de todas as variáveis na análise.

Depois de validados esses pressupostos, o próximo passo consiste em efetuar a análise preliminar das variáveis independentes. O teste de igualdade entre as médias revela o potencial de cada um dos sete fatores em separar os grupos. Dessa maneira, os fatores que apresentaram $\alpha<0,050$ passaram no pressuposto da igualdade das matrizes de variância e covariância, sendo, portanto, significantes na diferenciação entre os grupos.

Portanto, os fatores que mais se distinguem na análise são, nesta ordem: "estrutura de funcionamento", "relações interpessoais", "posicionamento da empresa perante o mercado" e "estratégias de melhoria". Este último fator, apesar de não ser não significativo a 0,050, apresenta elevado valor de F, sendo, portanto, considerado como discriminante das características organizacionais (Tabela 1).

Entretanto, de acordo com Belfiore, Fávero e Angelo (2005), a estatística lambda de Wilks oferece informações referentes às diferenças entre os grupos. O índice é obtido pela razão da variação dentro dos grupos (variação não explicada) sobre a variação total. O resultado varia entre $0,000 \mathrm{e}$ 1,000 , e pequenos valores indicam a existência de grandes diferenças entre os grupos, enquanto valores elevados indicam ausência de diferenças entre eles. Como todos os valores resultantes do lambda de Wilks são próximos de 1,000, concluise que o nível de diferenciação desses fatores é baixo, conforme apresentado na Tabela 1.

A importância das funções discriminantes geradas pode ser visualizada na Tabela 2. Como os autovalores resultantes dessa análise estão muito afastados de 1,000, conclui-se que a variação entre os grupos, explicada pela função discriminante, é alta. Contudo, o resultado da correlação canônica também apresenta valores afastados de 1,000, demonstrando que as quatro funções discriminantes obtidas pela análise possuem baixo poder de discriminação.
Os valores destacados na Tabela 3 revelam a ordem de grandeza da correlação simples entre as funções e as variáveis discriminantes. Essa matriz destaca as variáveis que realmente discriminam a amostra. Quanto maiores forem os coeficientes, em valor absoluto, mais a função discriminante detém a informação contida nessas variáveis.

Verifica-se, portanto, que o fator "dinâmica de crescimento" faz parte da primeira função e os fatores "estrutura de funcionamento" e "posicionamento perante o mercado", compõem a segunda função. Os outros quatro fatores integram as funções três e quatro, consideradas não significantes segundo a estatística de lambda de Wilks por apresentarem nível de significância inferior a 0,050 .

É interessante destacar que a "estrutura de funcionamento" e o "posicionamento perante o mercado" discriminam, de forma muito similar, a segunda função (Tabela 3), uma vez que, de certa forma, um fator é consequência do outro, segundo os principais autores da área de estratégia (PORTER, 1993; MINTZBERG, 2003). Além disso, eles se relacionam com o primeiro fator já que as características do mercado influenciam na escolha do posicionamento da empresa e este posicionamento determina, em grande parte, a configuração da estrutura organizacional.

A Figura 3 indica a posição do centroide de cada um dos cinco segmentos. Percebe-se que há uma proximidade muito grande entre todos os centroides, especialmente aqueles que representam os segmentos residencial, industrial e comercial, e infraestrutura, indicando que não há uma diferenciação significativa das características organizacionais entre eles. Entretanto, as empresas de serviços especializados e de construção industrializada se distinguem umas das outras e, também, do primeiro grupo formado. Essa diferença, de certa forma, já era esperada, em função das diferenças entre os produtos/serviços ofertados e do mercado de atuação de cada um desses três grupos de empresas.

Tabela 1 - Teste de igualdade entre as médias

\begin{tabular}{l|c|c|c}
\hline \multicolumn{3}{c}{ Teste de igualdade entre as médias } \\
\hline & $\begin{array}{c}\text { Lambda de } \\
\text { Wilks }\end{array}$ & F & Sig. \\
\hline Estratégias de melhoria & 0,931 & 2,100 & 0,085 \\
\hline Comportamento do indivíduo no trabalho & 0,979 & 0,607 & 0,658 \\
\hline Estrutura de funcionamento & 0,892 & 3,414 & 0,011 \\
\hline Dinâmica de crescimento & 0,955 & 1,317 & 0,268 \\
\hline Estilo de gestão & 0,954 & 1,353 & 0,255 \\
\hline Relações interpessoais & 0,894 & 3,333 & 0,013 \\
\hline Posicionamento perante o mercado & 0,914 & 2,646 & 0,037 \\
\hline
\end{tabular}


Tabela 2 - Autovalores

\begin{tabular}{c|c|c|c}
\hline Função & Autovalores & \% da variância & Correlação canônica \\
\hline 1 & 0,248 & 43,3 & 0,446 \\
\hline 2 & 0,215 & 37,5 & 0,421 \\
\hline 3 & 0,057 & 10,0 & 0,233 \\
\hline 4 & 0,052 & 9,1 & 0,222 \\
\hline
\end{tabular}

Tabela 3 - Matriz estrutural

\begin{tabular}{l|c|c|c|c}
\hline \multicolumn{4}{c}{ Matriz estrutural } \\
\cline { 2 - 5 } & \multicolumn{4}{c}{ Função } \\
\cline { 2 - 5 } & $\mathbf{1}$ & $\mathbf{2}$ & $\mathbf{3}$ & $\mathbf{4}$ \\
\hline Dinâmica de crescimento & $\mathbf{0 , 3 6 9}$ & 0,218 & $-0,134$ & 0,172 \\
\hline Comportamento do indivíduo no trabalho & $-0,276^{*}$ & $-0,058$ & $-0,145$ & $-0,109$ \\
\hline Estrutura de funcionamento & 0,370 & $\mathbf{0 , 5 9 2}$ & 0,364 & $-0,273$ \\
\hline Posicionamento perante o mercado & $-0,072$ & $\mathbf{0 , 5 8 5}$ & $-0,422$ & 0,409 \\
\hline Estilo de gestão & 0,299 & $-0,152$ & $\mathbf{0 , 5 9 0}$ & 0,120 \\
\hline Relações interpessoais & $-0,556$ & 0,229 & $\mathbf{0 , 5 6 7}$ & 0,473 \\
\hline Estratégias de melhoria & 0,341 & $-0,293$ & $-0,082$ & $\mathbf{0 , 7 1 7}$ \\
\hline
\end{tabular}

Figura 3 - Posição dos centroides

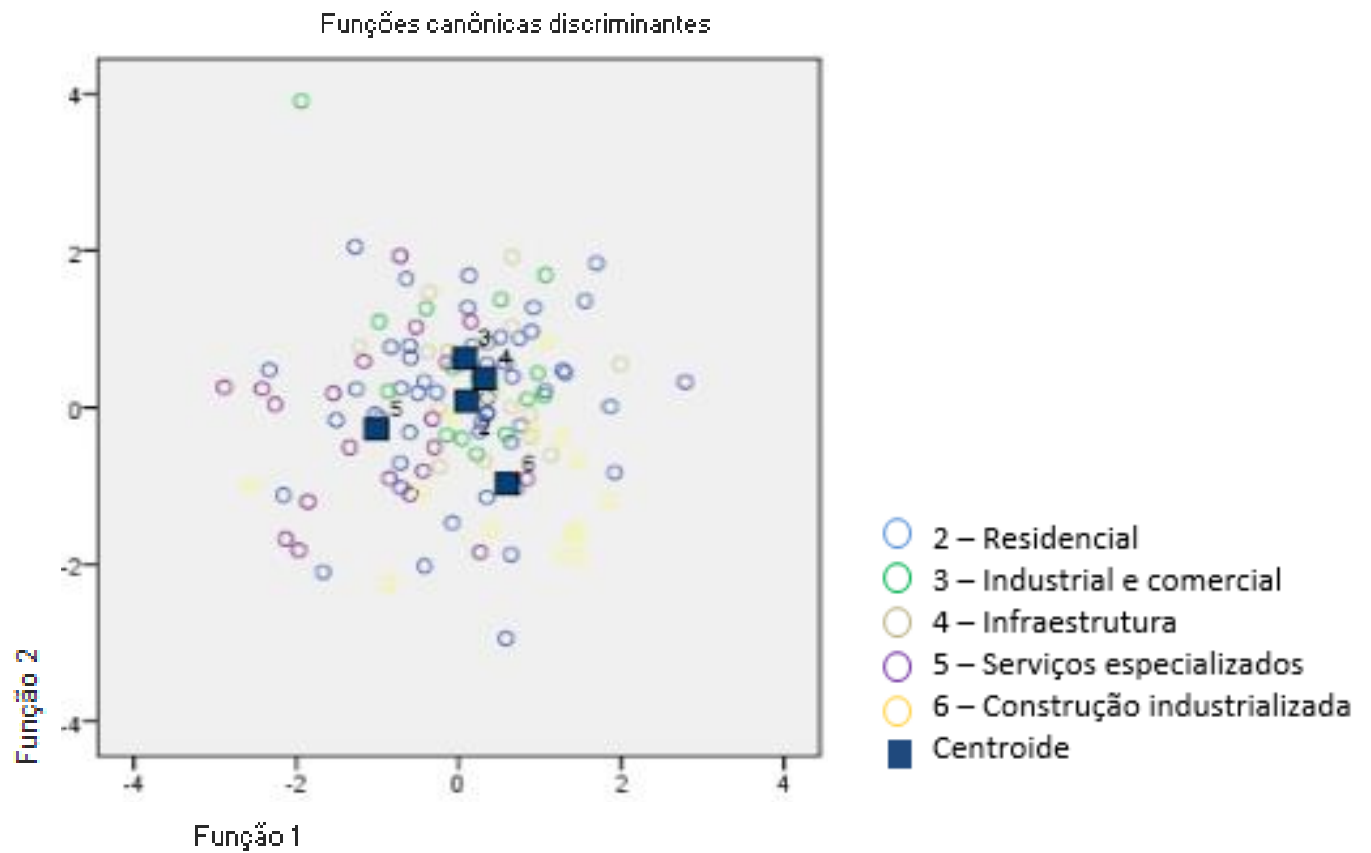

A conclusão dessa análise discriminante é obtida através da verificação da eficácia da classificação das observações originais. $O$ percentual de cada segmento classificado corretamente pode ser identificado na diagonal da matriz. A Tabela 4 demonstra que $50,8 \%$ dos casos originais foram corretamente classificados.

Com o intuito de verificar se o percentual de elementos classificados corretamente é satisfatório, aplica-se o teste $\mathrm{Q}$ de Press. Como o resultado obtido para Q de Press de 70,18 é superior ao valor crítico tabelado da distribuição do Qui-quadrado, $\chi^{2} \mathrm{n}=13,277$, para quatro graus de liberdade (GUJARATI, 2006), admite-se que a precisão da classificação para a amostra em análise excede em um nível estatisticamente significante a classificação ao acaso, validando o uso da análise discriminante nesta pesquisa. 
Tabela 4 - Resultados de classificação

\begin{tabular}{|c|c|c|c|c|c|c|c|}
\hline \multicolumn{8}{|c|}{ Resultados de classificação } \\
\hline & \multirow{2}{*}{$\begin{array}{c}\text { Atividade } \\
\text { Principal } \\
\text { (Segmento) }\end{array}$} & \multicolumn{5}{|c|}{ Associação prevista do grupo } & \multirow[b]{2}{*}{ Total } \\
\hline & & Residencial & $\begin{array}{c}\text { Industrial e } \\
\text { comercial }\end{array}$ & Infraestrutura & $\begin{array}{c}\text { Serviços } \\
\text { especializados }\end{array}$ & $\begin{array}{c}\text { Construção } \\
\text { industrializada }\end{array}$ & \\
\hline \multirow{5}{*}{ N. } & Residencial & 41 & 1 & 0 & 6 & 3 & 51 \\
\hline & $\begin{array}{l}\text { Industrial e } \\
\text { comercial }\end{array}$ & 12 & 2 & 1 & 0 & 0 & 15 \\
\hline & Infraestrutura & 14 & 0 & 3 & 0 & 0 & 17 \\
\hline & $\begin{array}{l}\text { Serviços } \\
\text { especializados }\end{array}$ & 10 & 1 & 0 & 8 & 1 & 20 \\
\hline & \begin{tabular}{|l|} 
Construção \\
industrializada \\
\end{tabular} & 8 & 0 & 0 & 1 & 6 & 15 \\
\hline \multirow{5}{*}{$\%$} & Residencial & 80,4 & 2,0 & 0,0 & 11,8 & 5,9 & 100,0 \\
\hline & \begin{tabular}{|l} 
Industrial e \\
comercial
\end{tabular} & 80,0 & 13,3 & 6,7 & 0,0 & 0,0 & 100,0 \\
\hline & Infraestrutura & 82,4 & 0,0 & 17,6 & 0,0 & 0,0 & 100,0 \\
\hline & \begin{tabular}{|l|} 
Serviços \\
especializados \\
\end{tabular} & 50,0 & 5,0 & 0,0 & 40,0 & 5,0 & 100,0 \\
\hline & \begin{tabular}{|l} 
Construção \\
industrializada
\end{tabular} & 53,3 & 0,0 & 0,0 & 6,7 & 40,0 & 100,0 \\
\hline
\end{tabular}

\section{Conclusão}

Nesta pesquisa identificaram-se sete fatores determinantes das características organizacionais das empresas do subsetor da construção. São eles: a dinâmica de crescimento, o comportamento do indivíduo no trabalho, a estrutura de funcionamento da empresa, o posicionamento perante o mercado, o estilo de gestão, as relações interpessoais e as estratégias de melhoria. A dinâmica de crescimento é fortemente afetada pelas condições de mercado e, portanto, pouco influenciada pela empresa. O comportamento do indivíduo no trabalho é, em grande parte, consequência das condições que lhes são oferecidas pela organização. Já o posicionamento, a estrutura, o estilo de gestão e as estratégias de melhoria que a empresa coloca em prática estão condicionados às suas próprias decisões.

Observa-se, portanto, que a maioria desses fatores determinantes está sob o domínio de decisão das próprias empresas, de modo que as ações que têm como objetivo aumentar a eficiência e a eficácia do seu negócio passam pela consciência interna de que as mudanças dependem mais do voluntarismo das empresas do que de aspectos externos.

Com relação às diferenças entre os segmentos, ficou evidente certa homogeneidade no desenvolvimento organizacional das empresas do subsetor da construção. A análise discriminante apontou um baixo nível de diferenciação entre os segmentos, enquanto a análise dos coeficientes da função discriminante mostrou que a diferença mais significativa ocorre na dinâmica de crescimento. Isso provavelmente advém dos diversos tipos de produto e/ou serviços que cada segmento oferta no mercado, da forma como se apresenta a demanda e do nível de concorrência característico de cada segmento.

No geral, os resultados mostram que o nível de desenvolvimento organizacional é semelhante ao dos cinco segmentos analisados, não havendo segmentos com um nível de desenvolvimento de destaque em relação aos demais.

Desse modo, conclui-se que as empresas dos diversos segmentos da construção se distribuem de maneira normal em relação às suas características organizacionais, não sendo possível caracterizar segmentos mais ou menos desenvolvidos dentro do subsetor. Entretanto, é necessário investigar o impacto de variáveis como o tamanho e a idade das empresas nas características organizacionais, bem como relacionar as características das empresas do subsetor da construção civil com as de outros subsetores industriais.

\section{Referências}

ABARESHI, A.; MOLLA, A. Greening Logistics and Its Impact on Environmental Performance: an absorptive capacity perspective. International Journal of Logistics Research and Applications, v. 16, n. 3, p. 209-226, 2013. 
AGUIAR, B.; CORREIA, W.; CAMPOS, F. Uso da Escala de Diferencial Semântico na Análise de Jogos. Salvador: Universidade Federal de Pernambuco, 2011.

\section{ANDREASSI, T.; SBRAGIA, R. Fatores} Determinantes do Grau de Inovatividade das Empresas: um estudo utilizando a técnica de análise discriminante. São Paulo: Universidade de São Paulo, 2001. Working Paper N. 01/004

BABBIE, E. Métodos de Pesquisas de Survey. Belo Horizonte: Ed. da UFMG, 1999.

BAKAR, A. H. A.; VIRGIYANTI, W.; TUFAIL, M. A. Knowledge Management Processes and Competitive Advantage in Construction Industry. Technical editor A. Xankishiyev, p. 81, 2012.

BAKKE, H. A.; MOURA LEITE, A. S. DE; SILVA, L. B. DA. Estatística multivariada: Aplicação da análise fatorial na engenharia de produção. Gestão Industrial, Ponta Grossa, v. 4, n. 4, p. 1-14, 2008.

BELFIORE, P. P.; FÁVERO, L. P. L.; ANGELO, C. F. DE. Análise Multivariada Para Avaliação do Comportamento de Grupos Supermercadistas Brasileiros. Administração em Diálogo, São Paulo, v. 7, n. 1, p. 53-75, 2005.

BELLAH, J.; ZELBST, P. J.; GREEN JUNIOR, K. W. Unique TQM Practices and Logistics Performance. International Journal of Productivity and Quality Management, v. 12, n. 1, p. 61-76, 2013.

\section{BENSON, L. T. H. Organizational flexibility} Management in Construction. Singapore, 2010. Thesis - National University of Singapore, 2010.

BEUREN, I. M.; FLORIANI, R.; HEIN, N. Indicadores de Inovação nas Empresas de Construção Civil de Santa Catarina que Aderiram ao Programa Brasileiro de Qualidade e Produtividade no Habitat (PBQP-H). Perspectivas em Gestão \& Conhecimento, v. 4, n. 1, p. 161$178,2014$.

BISQUERRA, R.; SARRIERA, J. C.; MARTÍNEZ, F. Introdução à Estatística: enfoque informático com o pacote estatístico SPSS. Porto Alegre: Artmed, 2007.

BURNS, T.; STALKER, G.M. The Management of Innovation. London: Tavistock, 1961.

CAMERON, I.; HARE, B.; DUFF, R. An Analysis of Safety Advisor Roles and Site Safety Performance. Engineering, Construction and Architectural Management, v. 20, n. 5, p. 505521, 2013.
CHANG, S. J.; CHOI, U. Strategy, Structure and Performance of Korean Business Groups: a transactions cost approach. The Journal of Industrial Economics, v. 37, n. 2, p. 141-158, dec. 1988.

CHEUNG, S. O.; WONG, P. S. P.; LAM, A. L. An Investigation of the Relationship Between Organizational Culture and the Performance of Construction Organizations. Journal of Business Economics and Management, v. 13, n. 4, p. 688704, 2012.

CHILESHE, N.; JOHN KIKWASI, G. Critical Success Factors for Implementation of Risk Assessment and Management Practices Within the Tanzanian Construction Industry. Engineering, Construction and Architectural Management, v. 21, n. 3, p. 291-319, 2014.

COMREY, A. L.; LEE, H. B. A First Course in Factor Analysis. [S.1.]: Psychology Press, 2013.

COSTELLO, A. B. Getting the Most From Your Analysis. Pan, v. 12, n. 2, p. 131-146, 2009.

CURETON, E. E.; D'AGOSTINO, R. B. Factor Analysis: an applied approach. [S.1]: Psychology Press, 2013.

DAWSON, S. Analysing Organisations. London: MacMillan, 1992.

DIKMEN, I.; BIRGONUL, M. T.; KIZILTAS, S. Prediction of Organizational Effectiveness in Construction Companies. Journal of Construction engineering and Management, v. 131, n. 2, p. 252-261, fev. 2005.

FREITAS, H. et al. O Método de Pesquisa Survey. Revista de Administração da USP, São Paulo, v. 35, n. 3, p.105-112, jul./set. 2000.

GUJARATI, D. N. Econometria Básica. Rio de Janeiro: Elsevier, 2006.

HAIR JUNIOR., J. F. et al. Fundamentos de Métodos de Pesquisa em Administração. Porto Alegre: Bookman, 2005.

HÅKANSSON, H.; JAHRE, M. Economic Logics in the Construction Industry. Arcom Proceedings, London, v. 2, p. 1063-1073, sep. 2005.

HALL, R. H. Organizações. Estruturas, Processos e Resultados. 8. ed. São Paulo: Pearson Prentice Hall, 2004.

HANDA, V.; ADAS, A. Predicting the Level of Organizational Effectiveness: a methodology for the construction firm. Construction Management \& Economics, v. 14, n. 4, p. 341-352, 1996. 
HORTA, I. M.; CAMANHO, A. S. Competitive Positioning and Performance Assessment in the Construction Industry. Expert Systems with Applications, v. 41, n. 4, p. 974-983, Mar. 2014. INSTITUTO BRASILEIRO DE GEOGRAFIA E ESTATÍSTICA. Pesquisa Anual da Indústria da Construção. Rio de Janeiro, 2011. Disponível em: $<$ http://loja.ibge.gov.br/pesquisa-anual-daindustria-da-construc-o-2011.html >. Acesso em: 25 ago. 2013

\section{INSTITUTO DE EDUCAÇÃO TECNOLÓGICA.}

Construção Civil: mercado cresce no país e aponta grandes desafios no setor. Disponível em: <http://www.techoje.com.br/site/techoje/categoria/ detalhe_artigo/1157>. Acesso em: 24 mar. 2014.

ISIK, Z.; ARDITI, D.; BIRGONUL, M. T. Impact of Resources and Strategies on Construction Company Performance. Journal of Management in Engineering, v. 26, n. 1, p. 9-18, 2010.

KIM, H. J.; REINSCHMIDT, K. F. Market Structure and Organizational Performance of Construction Organizations. Journal of Management in Engineering, v. 28, n. 2, p. 212220, 2011.

KIM, S. Organization and Managerial Environment of the Korean Construction Industry. Construction Management \& Economics, v. 15, n. 5, p. 409-419, 1997.

KOH, T. Y.; ROWLINSON, S. Relational Approach in Managing Construction Project Safety: a social capital perspective. Accident Analysis \& Prevention, v. 48, p. 134-144, 2012.

KRAINER, C. W. M. et al. Análise do Impacto da Implantação de Sistemas ERP nas Características Organizacionais das Empresas de Construção Civil. Ambiente Construído, Porto Alegre, v. 13, n. 3, p. 117-135, 2013, jul./set. 2013.

LANSLEY, P. Analysing Construction Organizations. Construction Management and Economics. v. 12, n. 4, p. 337-348, 1994.

LINGARD, H.; COOKE, T.; GHARAIE, E. A Case Study Analysis of Fatal Incidents Involving Excavators in the Australian Construction Industry. Engineering, Construction and Architectural Management, v. 20, n. 5, p. 488-504, 2013.

MAINARDES, C. W. Análise do Impacto de Sistemas Integrados de Gestão na Maturidade Organizacional em Empresas de Construção Civil. Curitiba, 2012. 283 f. Dissertação (Mestrado em Engenharia Civil) - Escola de Engenharia, Universidade Tecnológica Federal do Paraná, Curitiba, 2012.
MAROCO, J. Análise Estatística com Utilização do SPSS. Lisboa: Edições Sílabo, 2003.

MAROCO, J.; GARCIA-MARQUES, T. Qual a Fiabilidade do Alfa de Cronbach? Questões Antigas e Soluções Modernas? Laboratório de Psicologia, Lisboa, v. 4, n. 1, p. 65-90, 2006.

MAXIMIANO, A. C. A. Introdução à Administração. São Paulo: Atlas, 2000.

MINTZBERG, H. Criando Organizações Eficazes: estrutura em cinco configurações. São Paulo: Atlas, 2003.

MINTZBERG, H. Structure in Five Designing Effective Organizations. New York: Prentice Hall, 1983.

MOHAMMED ALASHWAL, A.; ABDULRAHMAN, H. Aspects of Project Learning in Construction: a socio-technical model.

Construction Innovation, v. 14, n. 2, p. 229-244, 2014.

OLIVEIRA. D. P. R. Sistemas, Organização e Métodos: uma abordagem gerencial. 11. ed. São Paulo: Atlas, 2000.

OZAKI, A. M. Estrutura Organizacional Para a Realização de Negócios Eletrônicos em Empresas Tradicionais: um estudo de caso. São Paulo, 2003. Dissertação (Mestrado em Administração) - Escola de Administração, Universidade de São Paulo, São Paulo, 2003.

PELLICER, E. et al. Construction Management. Oxford: Wiley Blackwell, 2014.

PERDIGÃO, D. E.; HERLINGER, M.; WHITE, O. M. Teoria e Prática da Pesquisa Aplicada. Rio de Janeiro: Elsevier, 2012.

PINTO, R. L. Evolução da Estrutura Organizacional ao Longo do Ciclo de Vida do Projeto: um estudo de caso. São Paulo, 2002. Tese (Doutorado em Administração) - Faculdade de Economia, Administração e Contabilidade, Universidade de São Paulo, São Paulo, 2002.

PORTER M. E. Vantagem Competitiva. Rio de Janeiro: Ed. Campus, 1993.

PRESCOT, R. Em Alerta: o baixo crescimento do PIB e os indicadores macroeconômicos vem afetando a construção civil, mas isto não significa que o setor esteja diante de uma crise. Construção e Mercado, São Paulo, v. 156, jul. 2014.

RAZAK BIN IBRAHIM, A. et al. Analyzing the Dynamics of the Global Construction Industry: past, present and future. Benchmarking: An International Journal. v. 17, n. 2, p. 232-252, 2010 . 
ROBBINS, S. Comportamento Organizacional. São Paulo: Prentice Hall, 2002.

RODRIGUES, M. C. P. Potencial de Desenvolvimento dos Municípios Fluminenses: uma metodologia alternativa ao IQM, com base na análise fatorial exploratória e na análise de clusters. Caderno de Pesquisas em Administração, São Paulo, v. 9, n. 1, p. 75-89, 2002.

ROSTAMI, A. et al. Risk Management Implementation in Small and Medium Enterprises in the UK Construction Industry. Engineering, Construction and Architectural Management, v. 22, n. 1, p. 91-107, 2015.

\section{SAMARTINI, A. L. S. Comparação Entre} Métodos de Mensuração da Importância de Atributos em Produtos e Serviços. São Paulo: GV Pesquisa, 2006.

SEGERSTEDT, A.; OLOFSSON, Th. Supply Chains in the Construction Industry. Supply Chain Management: An International Journal, v. 15, n. 5, p. 347-353, 2010.

SHEN, Y. et al. Empirical Investigation of Factors Contributing to the Psychological Safety Climate on Construction Sites. Journal of Construction Engineering and Management, v. 141, n. 7, 2015. SHIRAZI, B.; LANGFORD, D. A.; ROWLINSON, S. M. Organizational Structures in the Construction Industry. Construction Management \& Economics, v. 14, n. 3, p. 199212, 1996.

SOUZA, A. L. Notas de aula da disciplina ENF 796 - Problemas Especiais III (Técnicas Multivariadas Aplicadas em Manejo de Florestas). Análise discriminante aplicada a engenharia florestal. DEF/UFV. Viçosa, 2006.

STONER,J. A. F.; FREEMAN, R. E. Administração. 56. ed. Rio de Janeiro: LTC, 1999.

TABASSI, A. A.; RAMLI, M.; BAKAR, A. H. A. Effects of Training and Motivation Practices on Teamwork Improvement and Task Efficiency: the case of construction firms. International Journal of Project Management, v. 30, n. 2, p. 213-224, 2012.
VASCONCELLOS, E.; HEMSLEY, J. R. Estrutura das Organizações. 4. ed. São Paulo: Cengage Learning Edições, 2002.

VICINI, L.; MENDONÇA, A. Análise Multivariada da Teoria à Prática. Santa Maria: UFSM, CCNE, 2005.

VIVANCOS, A. G. Estruturas Organizacionais de Empresas Construtoras de Edifícios em Processo de Implementação de Sistemas de Gestão de Qualidade. São Paulo, 2001.

Dissertação (Mestrado em Engenharia) - Escola Politécnica, Universidade de São Paulo, São Paulo, 2001.

WOODWARD, J.; DAWSON, S.; WEDDERBURN, D. Industrial Organization: THEORY and practice. London: Oxford University Press, 1965.

YANG, H.; LU, W. Niche Comparisons: toward a new approach for analysing competition and organizational performance in the international construction market. Construction Management and Economics, v. 31, n. 4, p. 307-321, 2013.

YUKI, W. S. Análise das Relações Entre as Características da Estrutura Organizacional e o Nível de Desenvolvimento dos Processos Gerenciais de Empresas de Construção Civil. Curitiba, 2011. 256 f. Dissertação (Mestrado em Engenharia Civil) - Escola de Engenharia, Civil, Universidade Tecnológica Federal do Paraná. Curitiba, 2011.

ZAYED, T.; ELWAKIL, E.; AMMAR, M. A Framework for Performance Assessment of Organizations in the Construction Industry. International Journal of Architeture, Engineering and Construction, v. 1, n. 4, p. 199212, dec. 2012.

ZHAI, X.; LIU, A. M. M.; FELLOWS, R. Role of Human Resource Practices in Enhancing Organizational Learning in Chinese Construction Organizations. Journal of Management in Engineering, v. 30, n. 2, p. 194-204, 2013. 
ANEXO - MATRIZ DE COMPONENTES ROTACIONADOS

\begin{tabular}{|c|c|c|c|c|c|c|c|}
\hline \multicolumn{8}{|c|}{ Matriz de componentes rotacionados } \\
\hline & \multicolumn{7}{|c|}{ Fatores } \\
\hline & 1 & 2 & 3 & 4 & 5 & 6 & 7 \\
\hline $\mathbf{X 2 9}$ & $-0,062$ & $-0,135$ & 0,222 & $-0,031$ & $\mathbf{0 , 7 8 6}$ & $-0,005$ & 0,139 \\
\hline $\mathbf{X 3 0}$ & 0,190 & 0,106 & $\mathbf{0 , 6 8 9}$ & 0,243 & 0,221 & 0,067 & 0,137 \\
\hline X31 & 0,250 & 0,200 & 0,150 & 0,090 & $\mathbf{0 , 7 1 2}$ & $-0,019$ & $-0,012$ \\
\hline $\mathbf{X 3 2}$ & 0,218 & 0,193 & 0,566 & 0,119 & 0,252 & $-0,019$ & $-0,135$ \\
\hline X33 & 0,087 & 0,305 & $\mathbf{0 , 6 7 6}$ & 0,074 & 0,289 & 0,096 & $-0,090$ \\
\hline $\mathbf{X 3 4}$ & 0,075 & 0,374 & $-0,069$ & 0,084 & 0,528 & 0,277 & 0,110 \\
\hline $\mathbf{X 3 5}$ & $-0,280$ & 0,373 & $-0,291$ & 0,068 & 0,245 & $-0,146$ & 0,338 \\
\hline $\mathbf{X 3 6}$ & 0,151 & $-0,163$ & 0,757 & 0,070 & $-0,119$ & $-0,029$ & 0,085 \\
\hline $\mathbf{X 3 7}$ & 0,271 & 0,406 & 0,471 & 0,048 & $-0,089$ & 0,160 & 0,083 \\
\hline X38 & 0,180 & 0,149 & 0,066 & $\mathbf{0 , 7 9 5}$ & 0,093 & 0,092 & $-0,093$ \\
\hline X39 & $-0,107$ & 0,506 & 0,098 & 0,321 & 0,066 & $\mathbf{0 , 5 4 1}$ & 0,134 \\
\hline $\mathrm{X40}$ & 0,287 & $\mathbf{0 , 7 8 8}$ & $-0,029$ & 0,068 & 0,063 & $-0,013$ & 0,062 \\
\hline $\mathrm{X41}$ & 0,231 & $\begin{array}{l}\mathbf{0 , 7 5 9} \\
\end{array}$ & 0,219 & $-0,025$ & 0,046 & $-0,147$ & 0,018 \\
\hline $\mathrm{X42}$ & $\mathbf{0 , 6 0 7}$ & 0,424 & 0,256 & $-0,112$ & $-0,042$ & $-0,133$ & $-0,140$ \\
\hline $\mathrm{X} 43$ & 0,480 & 0,125 & 0,320 & 0,275 & 0,227 & 0,182 & $-0,069$ \\
\hline X44 & 0,373 & 0,018 & 0,308 & $\mathbf{0 , 5 7 2}$ & 0,177 & 0,108 & $-0,128$ \\
\hline $\mathrm{X} 45$ & 0,181 & 0,311 & 0,441 & 0,407 & 0,212 & 0,308 & $-0,159$ \\
\hline $\mathrm{X46}$ & 0,512 & 0,239 & 0,333 & 0,248 & 0,189 & 0,128 & $-0,102$ \\
\hline $\mathrm{X} 47$ & 0,130 & 0,019 & $-0,001$ & $-0,086$ & 0,059 & 0,024 & $\mathbf{0 , 8 0 2}$ \\
\hline $\mathrm{X} 48$ & 0,365 & 0,005 & 0,200 & 0,323 & $-0,045$ & 0,389 & 0,397 \\
\hline X49 & $-0,132$ & 0,179 & $-0,142$ & $-0,033$ & $-0,112$ & $-\mathbf{0 , 7 2 9}$ & 0,063 \\
\hline X50 & 0,124 & $\mathbf{0 , 6 5 6}$ & 0,161 & 0,259 & 0,107 & $-0,064$ & $-0,066$ \\
\hline X51 & 0,508 & 0,099 & 0,121 & 0,086 & 0,090 & $-\mathbf{- 0 , 5 9 5}$ & $-0,054$ \\
\hline X52 & 0,721 & 0,179 & 0,232 & 0,169 & 0,041 & $-0,245$ & 0,122 \\
\hline X53 & 0,679 & 0,245 & 0,062 & 0,131 & $-0,049$ & $-0,234$ & 0,298 \\
\hline X54 & 0,735 & 0,071 & 0,049 & 0,091 & 0,203 & 0,186 & $-0,105$ \\
\hline X55 & $\mathbf{0 , 6 8 3}$ & 0,130 & 0,241 & 0,155 & 0,026 & 0,328 & 0,147 \\
\hline $\mathrm{X56}$ & 0,644 & 0,034 & 0,133 & 0,333 & $-0,050$ & $-0,036$ & 0,338 \\
\hline X57 & 0,109 & 0,074 & 0,113 & $\mathbf{0 , 7 6 5}$ & $-0,072$ & $-0,051$ & 0,115 \\
\hline
\end{tabular}

Alessandra Tourinho Maia

Núcleo de Ciências Exatas e Tecnológicas | Universidade Positivo | Rua Professor Pedro Viriato Parigot de Souza, 5300, Cidade Industrial |

Curitiba - PR - Brasil | CEP 81280-330 | Tel.: (41) 3317-3159 | E-mail: alessandra.tourinho@gmail.com

\section{Alfredo larozinski Neto}

Departamento de Construção Civil Universidade Tecnológica Federal do Paraná | Rua Deputado Heitor Alencar Furtado, 5000, Cidade Industrial | Curitiba - PR - Brasil | CEP 81280-340 | Tel.: (41) 3279-4500 Ramal 4573 | E-mail: iarozinski@utfpr.edu.br

\section{Revista Ambiente Construído}

Associação Nacional de Tecnologia do Ambiente Construído

Av. Osvaldo Aranha, $99-3^{\circ}$ andar, Centro

Porto Alegre - RS - Brasil

CEP 90035-190

Telefone: +55 (51) 3308-4084

Fax: +55 (51) 3308-4054

www.seer.ufrgs.br/ambienteconstruido

E-mail: ambienteconstruido@ufrgs.br 